\title{
BMJ Open Patient experience of diagnosis and management of spontaneous intracranial hypotension: a cross- sectional online survey
}

\author{
Sanjay Cheema (D , , Clare Joy, ${ }^{2}$ Jenny Pople, ${ }^{2}$ Jessica Snape-Burns, ${ }^{2}$ \\ Tamsin Trevarthen, ${ }^{2}$ Manjit Matharu (D) ${ }^{1}$
}

To cite: Cheema S, Joy C, Pople J, et al. Patient experience of diagnosis and management of spontaneous intracranial hypotension: a cross-sectional online survey. BMJ Open 2022;12:e57438. doi:10.1136/ bmjopen-2021-057438

- Prepublication history for this paper is available online. To view these files, please visit the journal online (http://dx.doi org/10.1136/bmjopen-2021 057438).

Received 03 October 2021 Accepted 05 January 2022

Check for updates

(c) Author(s) (or their employer(s)) 2022. Re-use permitted under CC BY-NC. No commercial re-use. See rights and permissions. Published by BMJ.

${ }^{1}$ Headache and Facial Pain Group, UCL Queen Square Institute of Neurology, London, UK

${ }^{2}$ CSF Leak Association, Strathpeffer, Scotland, UK

Correspondence to

Dr Manjit Matharu;

m.matharu@uclmail.net

\section{ABSTRACT}

Objectives To present the results of a survey of patients with spontaneous intracranial hypotension (SIH) secondary to spinal cerebrospinal fluid (CSF) leak, documenting the patient experience of its diagnosis and management as well as quantifying its impact on quality of life.

Design A cross-sectional anonymous online survey was designed in conjunction with the CSF Leak Association patient charity. The survey included questions on diagnosis, investigations and treatments received, as well as validated disability and quality of life questionnaires.

Participants Sixty-four patients with a confirmed diagnosis of SIH who were receiving treatment within the UK were included in the analysis. The mean age was 42.8 years, $94 \%$ were female and 43 had ongoing symptoms of SIH.

Results Patients who presented to their general practitioner with symptoms of SIH were seen an average three times before being referred to a specialist, and in just under half of patients, the diagnosis was not made by the first specialist they saw. There was variability in which investigations were performed and how urgently they were organised. The mean EuroQol (EQ-5D-5L) Visual Analogue Scale score was $36.4 / 100$ and median Headache Impact Test- 6 score was $68 / 78$ (very severe impact). More than half of the respondents reported that they had to amend work duties due to SIH, more than a quarter reported that they had lost their job and two-thirds reported that their condition had affected their financial health. Only 23.4\% of patients felt that they had received enough help and advice to manage their pain due to $\mathrm{SIH}$.

Conclusions SIH is a highly disabling disorder, affecting multiple domains, including pain, mobility, activities of daily living, financial circumstances and employment. Diagnostic delay and misdiagnosis are common, and currently there is a lack of consistency in the investigation and management of SIH in the UK.

\section{INTRODUCTION}

\section{Background}

Spontaneous intracranial hypotension $(\mathrm{SIH})$ secondary to spinal cerebrospinal fluid (CSF) leak is characterised in most cases by disabling orthostatic headache, and may also have a variety of accompanying symptoms,
Strengths and limitations of this study

- Patients were fundamentally involved in the design of the study and analysis of results.

- The online based survey ensuring anonymity aimed to increase the likelihood of honest feedback and a higher response rate, allowing a relatively large number of responses within the UK for what is a rare condition.

- The use of validated quality of life and disability questionnaires allows comparison of the impact of spontaneous intracranial hypotension with that of other conditions.

- Responses to the questions on diagnosis and previous treatments were retrospective, therefore, subject to recall bias.

- A participation bias may have existed, meaning that patients with a negative experience or more longstanding symptoms may have been more likely to complete the survey.

including nausea and vomiting, neck pain, tinnitus, dizziness or vertigo, hearing disturbance, visual disturbance, back pain and cognitive symptoms. ${ }^{1}$ Although the level of disability attributable to SIH has not been quantified, patients with SIH often need to spend the majority of the day lying flat and are unable to perform activities of daily living or their employment duties.

$\mathrm{SIH}$ is usually (but not always) associated with features of low CSF pressure on MRI of the brain. ${ }^{2}$ The first-line treatment of SIH is non-targeted lumbar epidural blood patch (EBP), with the first EBP being reported as successful in $64 \%$ of patients in a recent meta-analysis. ${ }^{1}$ Other patients may respond to repeated non-targeted EBP, targeted patching or surgical repair of the dural defect. The condition is recently becoming better understood, aided by the development of newer radiological techniques, for example, with the discovery of CSF venous fistulas. Despite 
this, it is recognised that the diagnosis of SIH is often delayed or misdiagnosed and treatment pathways are not well established, prolonging a potentially treatable condition. ${ }^{3}$

The experience of patients of the diagnosis and management of SIH has not previously been systematically studied in the literature. We sought to undertake a survey of patients in the UK with medically confirmed SIH due to spontaneous spinal CSF leak. One of the reasons for conducting the survey was to identify current barriers to diagnosis and treatment of SIH, in order to inform the development of a national consensus clinical guideline for the investigation and management of SIH.

\section{Objective}

To present the results of a survey of patients with SIH, documenting the patient experience of its diagnosis and management as well as quantifying its impact on quality of life.

\section{METHODS}

\section{Patient and public involvement}

Patient members of the CSF Leak Association, a UK-based charity promoting awareness of CSF leaks, were fundamentally involved in all aspects of the study, including the study design, recruitment of participants, analysis of data and interpretation of the results.

\section{Study design}

We performed a cross-sectional web-based survey of patients with SIH. The survey was hosted by the CSF Leak Association from March 2021 to April 2021 on the Snap Surveys platform. The survey was advertised on the CSF Leak Association website and via social media platforms Facebook, Instagram and Twitter. Responses to the survey were anonymous.

The survey included questions on the respondents' demographics, diagnoses, diagnostic pathway, investigations performed, treatments received, follow-up, advice given by medical professionals and healthcare service utilisation. The survey questions regarding demographic information and initial diagnostic pathway were asked of all respondents. Questions regarding investigations performed and treatments received were asked of only those respondents who said that they had been seen by a hospital specialist.

The survey also included the EQ-5D-5L quality of life measure, ${ }^{4}$ the Headache Impact Test- 6 (HIT-6) measure of headache-related disability, ${ }^{5}$ and the Hospital Anxiety and Depression Scale (HADS) questionnaire. ${ }^{6}$ These questionnaires were asked of only those patients who currently had ongoing symptoms of SIH. Several additional quality of life questions were devised specifically for this survey to assess the impact of SIH on employment and financial health, and were written so that they could be answered retrospectively, and these questions were asked of all respondents.

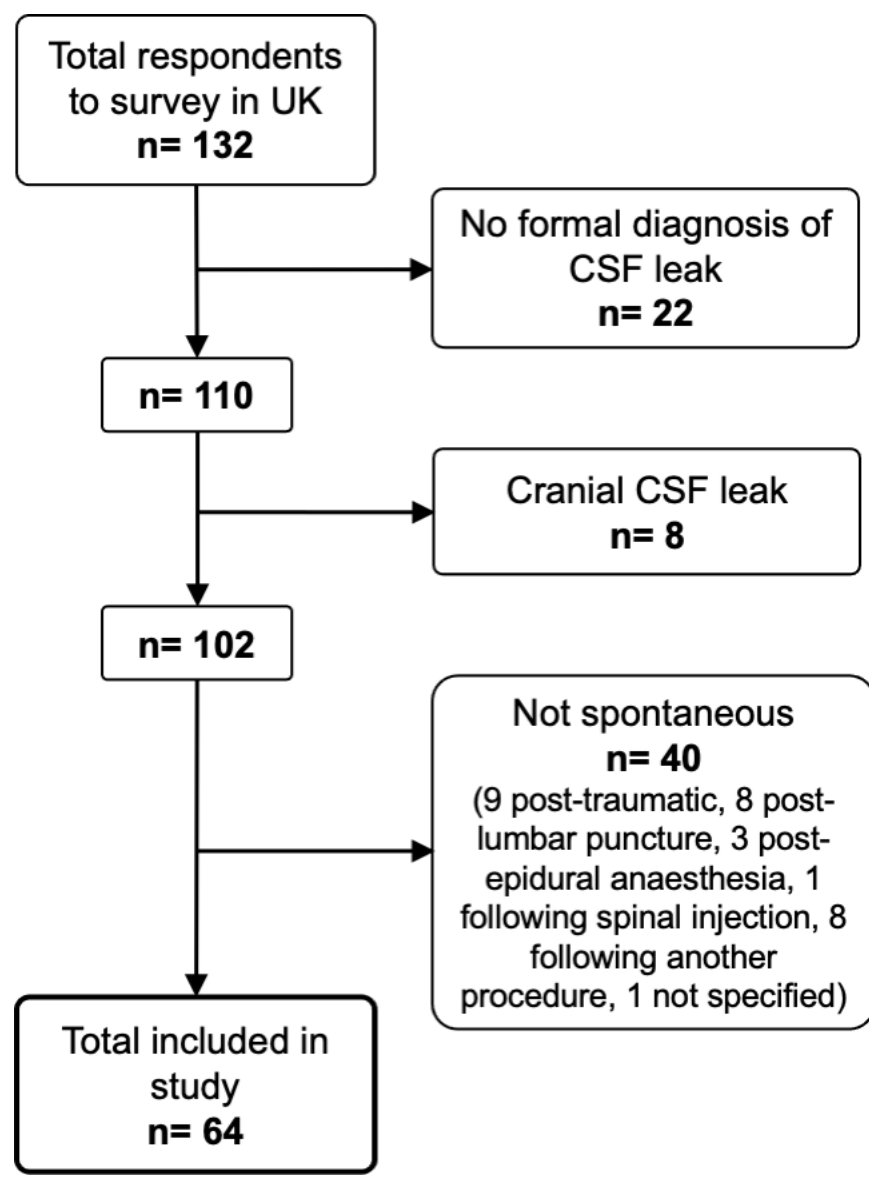

Figure 1 Flow diagram of survey respondents included in the study. CSF, cerebrospinal fluid.

\section{Participants}

Although the survey was open to respondents over 18 years of age in any country and with any type of CSF leak, respondents were only included in the analysis for this study if they reported that they had received a formal diagnosis of SIH and were receiving treatment in the UK. Convenience sampling was used; no formal statistical sample size calculation was performed.

\section{Statistical analysis}

Statistical analysis was performed using SPSS V.27. Normality assumptions were based on visual inspection of histograms and Kolmogorov-Smirnov test. Missing data were not imputed. Descriptive data were summarised as means with SD or medians with IQRs depending on the distribution of data. For group comparisons of nonnormally distributed continuous data, Mann-Whitney U tests were used, and for group comparisons of categorical variables $\chi^{2}$ tests were used.

\section{RESULTS}

\section{Participants}

There were 212 respondents to the survey, 64 of whom had a confirmed diagnosis of SIH due to spinal CSF leak, were receiving care within the UK and were, therefore, included in the final analysis (see figure 1). 
The mean age of respondents was 42.8 years (SD: 10.3 years, range: $20-65$ years), and 60/64 (94\%) were female. Just over two-thirds $(43 / 64,67.2 \%)$ had ongoing symptoms of SIH at the time of completing the survey. The median duration of SIH symptoms was 24 months (IQR: 53.5 months, range: $0-240$ months). The majority (52/64, $81.3 \%$ ) of respondents had experienced a single episode of SIH, 5/64 (7.8\%) had experienced two episodes and $7 / 64(10.9 \%)$ had experienced 3 or more episodes.

\section{Diagnostic pathway}

Patients first presented to their general practitioner (GP) in $33 / 59(55.9 \%)$ of cases. Of these, the median number of visits before being referred to a hospital specialist (usually a neurology department) was 3 (IQR: 4, range: 1-15). Patients first presented to an emergency department (ED) in 24/59 (40.7\%) of cases. Of these, $15(62.5 \%)$ were admitted to hospital, two $(8.3 \%)$ were discharged with an outpatient appointment and seven $(29.2 \%)$ discharged to see their GP.

The majority of respondents $(51 / 64,79.7 \%)$ had been seen by a hospital specialist, usually a neurologist. The median wait time to being seen by a hospital specialist was 3 weeks for patients who first presented to their GP (IQR: 9 weeks, range: 0-22 weeks) and 1 week for patients who first presented to an ED (IQR: 6 weeks, range: 0-16 weeks). This difference was not statistically different $(\mathrm{p}=0.302)$. Over half $(28 / 51,54.9 \%)$ had seen more than one neurologist for their condition. In 23/51 (45.1\%), the diagnosis of SIH was not received by the patient from the first specialist they were referred to but was later made by another specialist. The median time from symptom onset to receiving a diagnosis of SIH was two months (IQR: 6 months, range: $0-180$ months). The median time to diagnosis was 2.5 months in those who initially presented to their GP compared with one month in those who initially presented by ED, but this difference was not statistically significant $(\mathrm{p}=0.149)$.

On a scale of 1 (very easy) to 10 (very difficult) for how easy the patient felt it was to get a formal diagnosis for their condition, the median response was 6.5/10 (IQR: 6 , range: $1-10)$, with $13 / 50(26 \%)$ of patients giving a response of 10. In response to an additional free text question about the patient experience of been diagnosed with $\mathrm{SIH}$, the majority of responses were negative, selected responses to this question are given in box 1 .

\section{Investigations}

The most commonly performed investigation was MRI of the brain, which had been performed in 49/51 (96.1\%) of patients, with contrast in $75.5 \%$ of cases. The median wait time for MRI was fourweeks (IQR: 11 weeks, range: 0-56 weeks). In 7/49 (14.3\%) of the patients, the MRI of the brain was initially reported as normal, but later re-read by another radiologist as showing signs of SIH. In $5 / 37(13.5 \%)$ of the patients in whom the MRI was requested with contrast, the MRI needed to be repeated
Box 1 Selection of quotations demonstrating variation in patient experience of the diagnostic pathway of SIH

\section{Is there anything else about your experience of diagnosis that you would like to tell us?}

'Was sent home from A\&E twice before being admitted on the third trip to hospital even though a CSF leak was suspected at the first visit. I don't feel that the condition is taken seriously enough.'

'Local wait to see a neurologist was 9-12 months even when urgent. GP referred to Ambulatory Care at Hospital as felt it was the only option, but the general medicine consultants there thought that normal brain MRI and normal opening pressure meant no leak.'

'I've been left in pain for nearly 4 years. Been laying down for nearly all this time awaiting the new long-awaited CT myelogram to find leak/s.'

'I have seen four neurologists (three local, one London) and two neurosurgeons (neuroscience centre). It was a pain clinic physiotherapist that suggested a CSF leak so I made a private appointment with a CSF leak specialist (fifth neurologist) who confirmed SIH.'

'I was very lucky in that I was diagnosed within 10 days of symptoms onset. I had my first blood patch 2 days after diagnosis.

'My experience was difficult and I am very glad I have private healthcare. Trying to go through the NHS involved 3 NHS 111 calls, 3-4 GP appointments and an A\&E visit.'

'I feel that I was lucky with my diagnosis. Had the hospital not requested a neurologist to come to the ward I was in I would have been sent home with a different diagnosis entirely.'

'The neurologist offered me no treatment or follow-up appointments other than 1 box of codeine. Looking back, I can't believe how unwell I was, yet I was discharged with no treatment plan or follow-up care.' 'It happened not long after changing OCP so got repeatedly told it was hormonal migraine despite no migraine history and the symptoms clearly having orthostatic features.'

'Neurologist at my local hospital refused to believe in CSF leak telling me to just get on with it, saying it's daily chronic headaches and I'll have to learn to live with it.

A\&E, Accident and Emergency department; CSF, cerebrospinal fluid; GP, general practitioner; OCP, contraceptive pill; SIH, spontaneous intracranial hypotension.

as the contrast was not given or not given correctly at the first appointment.

In $17 / 51(33.3 \%)$ of patients, a lumbar puncture had been performed, five of these patients underwent two lumbar punctures, and four patients underwent three or more lumbar punctures. In 27/51 (52.9\%) of patients, either CT myelography (CTM) or digital subtraction myelography had been performed. The median delay to myelography being performed was eight weeks (IQR: 36 weeks, range: 1-150 weeks). In 4/51 (7.8\%) of patients, intracranial pressure monitoring had been performed.

\section{Treatment}

Twenty-six $(51 \%)$ of the respondents reported that they were initially advised to use conservative management, including bed rest. In 13 patients, this was recommended in parallel with an EBP being organised, and in 11 patients this was recommended for a specific period of time before an EBP was organised, with the period of time recommended ranging from one week to 12 weeks (median: 4.5 weeks, IQR: 5 weeks). Twenty-three (45.1\%) 
of the patients reported that they were advised to use analgesic medications, and $11(21.6 \%)$ said that they were prescribed a daily medication typically used for migraine or neuropathic pain (such as amitriptyline, topiramate or gabapentin). Nine patients $(17.6 \%)$ received at least one intravenous caffeine infusion.

The majority of respondents $(39 / 51,76.5 \%)$ had undergone at least one non-targeted EBP. The median wait time from the first EBP being requested to being performed was two weeks (IQR: 3 weeks, range: 0-16 weeks). In 10 patients $(26.3 \%)$, the first EBP was performed using radiological guidance, and three $(7.7 \%)$ of the patients were offered sedation. At least one adverse effect from blood patching was reported by 14/39 (35.9\%) of patients. The most common adverse effects were back pain lasting longer than four weeks in 10 patients $(25.6 \%)$, nerve root pain in six patients (15.4\%), sensory impairment in two patients $(5.1 \%)$ and arachnoiditis in one patient $(2.5 \%)$. Rebound high pressure symptoms were reported by $18 / 39(46.2 \%)$ of the patients and in six patients this was managed with medication. Fourteen patients (35.9\%) reported that they did not receive a follow-up appointment after their first EBP. In those who were followed-up, the time interval ranged from less than a week to 52 weeks (median: 5 weeks, IQR: 8 weeks).

Five patients were treated with a targeted fibrin glue patch and five patients were treated with surgery. The median wait time for fibrin glue patching was 12 weeks (IQR: 17 weeks, range: 2-36 weeks) and surgery was 10 weeks (IQR: 26 weeks, range: 4-52 weeks).

Eleven patients $(21.6 \%)$ had been offered physiotherapy or rehabilitation as part of recovery from SIH, eight of whom $(72.7 \%)$ found this helpful. Twelve patients $(14.1 \%)$ had been referred to a pain clinic, and nine patients $(14.1 \%)$ had been referred to mental health services. Overall, only 15 patients $(23.4 \%)$ felt that they had received enough help and advice to manage their pain due to SIH. Only 3/29 (10.3\%) of the patients in whom it was applicable had been offered any advice or guidance regarding pregnancy or labour and SIH.

\section{Disability and quality of life}

More than half of the respondents $(37 / 62,60 \%)$ reported that they had to amend work duties due to SIH, and more than a quarter $(16 / 62,26 \%)$ reported that they had lost their job. Two-thirds $(42 / 63,67 \%)$ reported that their condition had affected their financial health, 17/63 $(27 \%)$ said that they were receiving state-funded benefits due to their condition and 3/63 (5\%) reported that they had fundraised to support their medical costs.

The EQ-5D-5L questionnaire was completed by $42 / 43$ $(98 \%)$ of the respondents who had ongoing symptoms. A moderate or greater impact on quality of life was scored in $54 \%$ of the respondents for mobility, $39 \%$ for selfcare, $84 \%$ for usual activities, $88 \%$ for pain and $45 \%$ for depression or anxiety (see figure 2). On the EQ-5D-5L Visual Analogue Scale from 0 to 100 (where 0 is the worst

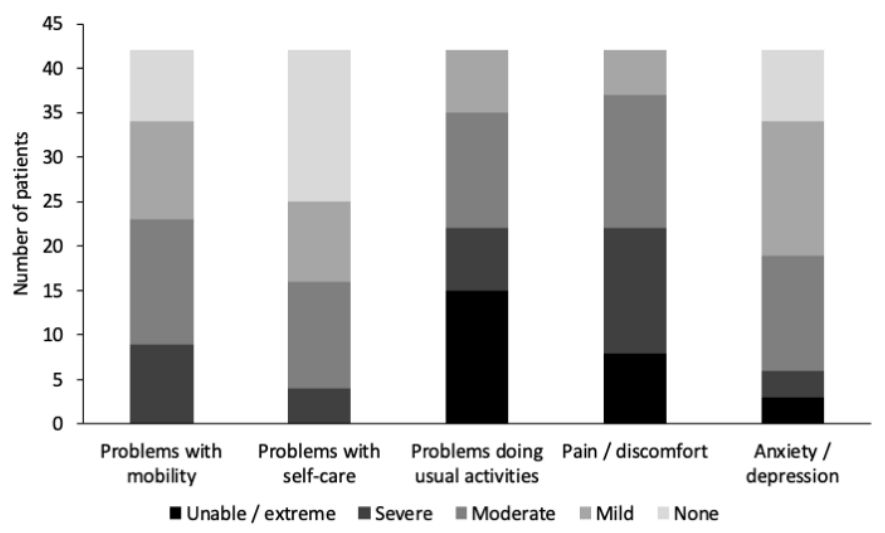

Figure 2 Proportion of patients with health status at each level of quality of life by EuroQol (EQ-5D-5L) dimension.

health you can imagine and 100 is the best health you can imagine), the mean score was 36.4 (SD: 20.8).

The HIT-6 questionnaire was completed by $39 / 43$ $(91 \%)$ of the respondents who had ongoing symptoms. The median HIT-6 score was 68 (IQR: 65-74), and 37/39 $(94.9 \%)$ of the respondents were within the very severe impact range. The HADS questionnaire was completed by $42 / 43(98 \%)$ of the respondents who had ongoing symptoms. Using a cut-off score of $11,55 \%$ were in the abnormal range on the depression subscale and $38 \%$ on the anxiety subscale.

Selected responses to an additional free text question about the impact on quality of life due to SIH are given in box 2.

\section{DISCUSSION}

To the best of our knowledge, this is the largest published survey of the experience of patients with $\mathrm{SIH}$, and the first in the UK. It provides quantitative and qualitative data demonstrating the level of disability and quality of life in patients suffering SIH across multiple domains, including pain, mobility, activities of daily living, financial circumstances and employment. The survey shows that SIH is often recognised late by healthcare professionals, with patients often seeing their GP multiple times with symptoms before they are referred to a specialist, and then the diagnosis frequently not being made by the first specialist seen. There may also be an underrecognition of imaging signs of SIH by radiologists demonstrated by the number of patients whose MRI of the brain was initially reported as normal but later re-read as showing signs of intracranial hypotension. The survey highlights several delays in the pathway to diagnosis and management, including the time to specialist appointment (median delay of threeweeks), MRI of the brain (fourweeks), period of bed rest (if recommended) (4.5 weeks), EBP (two weeks) and CTM (eightweeks); and in those patients who required it, targeted fibrin patching (median delay 12 weeks) and surgery (median delay 10 weeks). These interventions are undertaken sequentially in most patients meaning that the majority of patients will wait 
Box 2 Selected quotations demonstrating impact of SIH on quality of life

\section{Do you have anything else you would like to share about areas of your life affected by your CSF leak?}

'A CSF leak affected every area of my life-it was profoundly disabling. I could not care for my three children alone as I could not lift them.' 'My disability was such a strain on my family my husband had a mental breakdown trying to cope with kids and financial responsibility.'

'I have lost my career because of it. I lost my job in September 2019. I just want to be able to work, but I am mostly bed bound and have been since February 2019.'

'I had to take 9 months off work and did not receive any sick pay. I had to spend my savings to fund my illness and to pay for the excess on my husband's private medical insurance policy.'

'I haven't been able to be upright for more than 1 hour a day due to severe pain from my leak. I haven't worked since my symptoms began. I need a lot of care and help from my husband. Because being upright for showering/bathing results in such painful symptoms I rarely shower properly.'

'To go from being a healthy young women exercising 6 days a week to almost completely bed bound is really hard, and when we are left at home in this condition for months on end waiting for treatment I think that our consultants should make sure our GPs are aware that we are likely to need extra support ... when we aren't able to be upright long enough to cook for ourselves or shower ....

'I effectively lost 2 years of my life due to my leak. I lost the job I loved and had worked so hard for. The effect of living with my symptoms for so long before I was diagnosed was profound. I struggled to cope with the simplest aspects of everyday life and contemplated suicide as a way out when I was at my lowest ebb.'

'The impact on my partner has been immense and not recognised just as much as the impact on my mental health was not recognised.'

'Life completely altered for me and my partner. Had to sell our business and move to smaller house. Partner currently on career break to look after me. We are severely restricted in finances and ability to live life. Don't see friends or family much.'

'The impact on your life outwith hospital, your family, your friends, your work, your pastimes, your mental health is the iceberg under the water. Doctors only see the tip. The wider impacts of a leak are numerous and severe, and support is all but non-existent. Being sent home by doctors to lie in a bed for months on end, with no support, no job, no life is soul destroying.'

CSF, cerebrospinal fluid; GPs, general practitioners; SIH, spontaneous intracranial hypotension.

longer than 12 weeks for treatment (see figure 3). This is important given that recent evidence has demonstrated that shorter symptom duration is the best predictor of response to surgery for SIH, with a cut-off of treatment within 12 weeks predicting a better outcome. ${ }^{7}$ It is likely that in a minority of patients, delays were exaggerated by the impact of the COVID-19 pandemic, although most patients were diagnosed and treated for SIH prior to the year 2020 and respondents were specifically asked for each intervention whether it had been delayed due to COVID19 , with less than $10 \%$ of respondents responding that it had done so for each intervention. The survey results also highlight the variability in current management pathways for SIH, including the interventions which are performed and urgency with which it is treated. Lumbar puncture was performed in many patients (sometimes more than once) despite it being recognised that CSF pressure is commonly normal in patients with SIH and low CSF opening pressure is no longer included in the diagnostic criteria for SIH. ${ }^{89}$ There is also variability in how EBPs are performed, for example, in the use of imaging guidance and/or sedation.

The study was conducted with, and predominantly by, patients who have suffered with the condition and have experienced the diagnostic and management pathway themselves. Patient and public involvement in research is thought to have multiple benefits in producing better quality research, which is more relevant to their needs. The use of a web-based survey allowed a relatively large number of responses for an uncommon condition. It was decided to open the survey to a wide group of respondents, rather than a pre-selected group of patients in order to gain real-world data in a variety of settings and locations around the UK and maximise the number of respondents. The anonymity of the survey allowed respondents to feel comfortable in reporting their experience honestly and reducing social desirability bias. The use of validated questionnaires of quality of life, headacherelated disability, anxiety and depression allowed objective assessment and quantification of the impact and disability attributable to SIH, which may be useful in raising awareness of the condition and funding for future research into $\mathrm{SIH}$.

This study has several limitations. Responses were retrospective and some respondents had experienced $\mathrm{SIH}$ several years previously; therefore, responses were subject to recall bias. Responses were self-reported, and although there is no reason to suspect that responses were not honest, their reliability cannot be confirmed. A participation bias also may have existed in the patients who completed the survey: patients with a complicated diagnostic and/or therapeutic course and patients with negative experience may be more likely to respond due to a desire to improve care for others, whereas patients in whom SIH was diagnosed and treated early may be less likely to have sought information from and be aware of the patient charity, and/or less motivated to complete the survey. The recruitment methods through the CSF Leak Association and advertisement on social media may have also biased the sample of patients toward a younger population who are more likely to use social media or search for healthcare information online. There was an overrepresentation of female respondents, which likely represents the known increased likelihood of females to respond to online surveys. ${ }^{10}$ These factors mean that the results may not be generalisable to SIH in other populations. Finally, the sample size of the study would ideally be larger, but this is limited by the relatively rare nature of $\mathrm{SIH}$, with the best estimate of its incidence at 3.7 per 100 000 of the population. ${ }^{11}$

The study supports previous evidence showing that misdiagnosis and diagnostic delay is common in $\mathrm{SIH}^{3}$ 


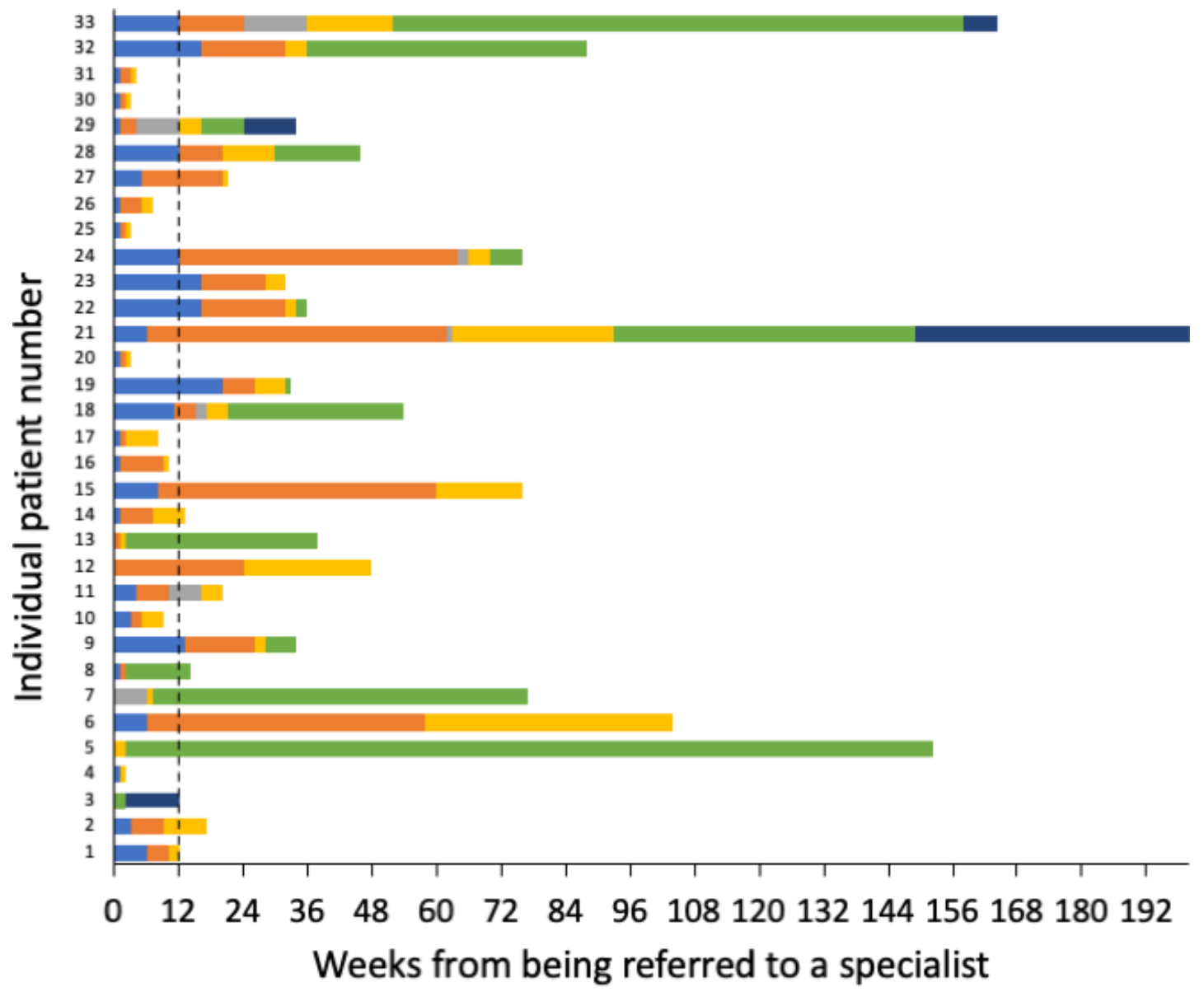

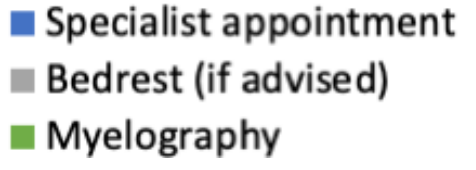

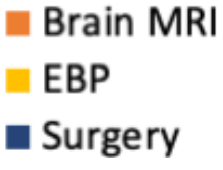

Figure 3 Delays from referral to a specialist to investigation and treatment. Bars represent cumulative wait time assuming the investigations/interventions were performed sequentially and there was no gap between each intervention being performed and the next being requested. Only those patients who reported their wait time for specialist appointment, MRI of the brain and nontargeted EBP are shown. The chart shows that only 1/3 of patients received their first EBP within 12 weeks of being referred to a specialist. EBP, epidural blood patch.

This study also provides evidence for the suspected high levels of disability suffered by patients with SIH. The mean EQ-5D Visual Analogue Scale score of 36.4 in this patient population is worse than published mean scores of 59.7 in multiple sclerosis and 52.0 in advanced Parkinson's disease. ${ }^{12} 13$ The mean HIT-6 score of 68.2 in this survey is comparable to a published mean score of 64.7 in a series of patients with SIH undergoing surgery for CSF-venous fistula, 65.5 in chronic migraine and 59.7 in idiopathic intracranial hypertension. ${ }^{14-16}$

The survey demonstrates the variability of investigation and management pathways in SIH, likely resulting in delays to effective diagnosis and treatment. There are several potential explanations for this. It is a rare condition, meaning outside of specialist centres most general neurologists, radiologists, anaesthetists and neurosurgeons are likely to only see a handful of cases of SIH in their career, leading to lack of awareness. The understanding of SIH has progressed in the past 10 years, which has often not passed into clinical practice, where a number of misconceptions commonly exist, some of which are highlighted in the patient reports given in box $1 .{ }^{17}$

This study gives support for the development of consensus clinical guidelines for the investigation and management of SIH based on the existing evidence base and highlights the need for further research into this condition in order to establish the optimal treatment pathway. Future research should ideally recruit patients at the time of diagnosis to confirm the efficacy of non-targeted epidural blood patching, identify factors which may predict prognosis and response to treatment, and demonstrate improvement in objective outcome measures. We hope that this study will increase awareness of SIH and its impact on quality of life, thereby improving patient care and motivating future research. 
Twitter Manjit Matharu @manjit_matharu

Acknowledgements All the respondents to the survey who gave up their time to share their experiences. The board of trustees of the CSF Leak Association who supported the study. Clare Sargeant for her help in the early planning stages and volunteers of the CSF Leak Association for testing the survey prior to launch. Members of the SIH specialist interest group who contributed to developing the survey questions.

Contributors SC: design of survey, analysis of data, interpretation of results, drafting and revising the manuscript. CJ: conception and design of survey, analysis of data, interpretation of results and revising the manuscript. JP: design of survey, analysis of data and interpretation of results. JS-B: design of survey, acquisition and analysis of data. TT: design of survey. MM: conception and design of survey, interpretation of results and revising the manuscript, and is the guarantor who accepts full responsibility for the finished work and/or the conduct of the study. All authors approved the final manuscript.

Funding The authors have not declared a specific grant for this research from any funding agency in the public, commercial or not-for-profit sectors.

Competing interests $\mathrm{SC}$ has no competing interests. CJ, JP, JS-B and TT are members of the CSF Leak Association and have experienced a CSF leak themselves. MM is chair of the medical advisory board of the CSF Leak Association; has served on advisory boards for Allergan, Autonomic Technologies, Eli Lilly, Novartis, Pfizer, Salvia and TEVA; has received payment for educational presentations from Allergan, electroCore, Eli Lilly, Novartis and TEVA; has received grants from Abbott, Medtronic and electroCore; and has a patent on system and method for diagnosing and treating headaches (W02018051103A1, issued).

Patient and public involvement Patients and/or the public were involved in the design, or conduct, or reporting, or dissemination plans of this research. Refer to the Methods section for further details.

Patient consent for publication Not applicable.

Ethics approval This study involves human participants. The purpose and content of the survey were approved by the board of trustees of the CSF Leak Association charity. No personally identifiable data were collected, and responses were anonymous from the point of entry. Participants were not recruited in connection with any use of any healthcare service. Research ethics committee approval was not required in accordance with the Health Research Authority's decision tool. In order to complete the survey, patients were required to consent to the data collected from the survey being used in a publication. This was discussed (via email) with the editorial production assistant (Rey Pordaliza) and reflected in the manuscript. Participants gave informed consent to participate in the study before taking part.

Provenance and peer review Not commissioned; externally peer reviewed.

Data availability statement Data are available upon reasonable request.

Open access This is an open access article distributed in accordance with the Creative Commons Attribution Non Commercial (CC BY-NC 4.0) license, which permits others to distribute, remix, adapt, build upon this work non-commercially, and license their derivative works on different terms, provided the original work is properly cited, appropriate credit is given, any changes made indicated, and the use is non-commercial. See: http://creativecommons.org/licenses/by-nc/4.0/.
ORCID iDs

Sanjay Cheema http://orcid.org/0000-0002-5438-6549

Manjit Matharu http://orcid.org/0000-0002-4960-2294

\section{REFERENCES}

1 D'Antona L, Jaime Merchan MA, Vassiliou A, et al. Clinical presentation, investigation findings, and treatment outcomes of spontaneous intracranial hypotension syndrome: a systematic review and meta-analysis. JAMA Neurol 2021;78:329.

2 Kranz PG, Tanpitukpongse TP, Choudhury KR, et al. Imaging signs in spontaneous intracranial hypotension: prevalence and relationship to CSF pressure. AJNR Am J Neuroradiol 2016;37:1374-8.

3 Schievink WI. Misdiagnosis of spontaneous intracranial hypotension. Arch Neurol 2003;60:1713-8.

4 Herdman M, Gudex C, Lloyd A, et al. Development and preliminary testing of the new five-level version of EQ-5D (EQ-5D-5L). Qual Life Res 2011;20:1727-36.

5 Kosinski M, Bayliss MS, Bjorner JB, et al. A six-item short-form survey for measuring headache impact: the HIT-6. Qual Life Res 2003;12:963-74.

6 Zigmond AS, Snaith RP. The hospital anxiety and depression scale. Acta Psychiatr Scand 1983;67:361-70.

7 Häni L, Fung C, Jesse CM, et al. Outcome after surgical treatment of cerebrospinal fluid leaks in spontaneous intracranial hypotension-a matter of time. J Neurol 2021 doi:10.1007/s00415-021-10710-7

8 Kranz PG, Tanpitukpongse TP, Choudhury KR, et al. How common is normal cerebrospinal fluid pressure in spontaneous intracranial hypotension? Cephalalgia 2016;36:1209-17.

9 Headache Classification Committee of the International Headache Society (IHS). The International classification of headache disorders, 3rd edition. Cephalalgia 2018;38:1-211.

10 Smith WG. Does gender influence online survey participation? A record-linkage analysis of university faculty online survey response behavior. San Jose State University, 2008.

11 Schievink WI, Maya MM, Moser FG. Incidence of spontaneous intracranial hypotension in a community. Beverly Hills, California, 2006-2020. Cephalalgia 2021;21:033310242110485.

12 Jones KH, Ford DV, Jones PA, et al. How people with multiple sclerosis rate their quality of life: an EQ-5D survey via the UK MS register. PLoS One 2013;8:e65640.

13 Schrag A, Selai C, Jahanshahi M, et al. The EQ-5D-a generic quality of life measure-is a useful instrument to measure quality of life in patients with Parkinson's disease. J Neurol Neurosurg Psychiatry 2000;69:67-73.

14 Lipton RB, Varon SF, Grosberg B, et al. OnabotulinumtoxinA improves quality of life and reduces impact of chronic migraine. Neurology 2011;77:1465-72.

15 Wang TY, Karikari IO, Amrhein TJ, et al. Clinical outcomes following surgical ligation of cerebrospinal Fluid-Venous fistula in patients with spontaneous intracranial hypotension: a prospective case series. Oper Neurosurg 2020;18:239-45.

16 Friedman DI, Quiros PA, Subramanian PS, et al. Headache in idiopathic intracranial hypertension: findings from the idiopathic intracranial hypertension treatment trial. Headache 2017;57:1195-205.

17 Kranz PG, Gray L, Amrhein TJ. Spontaneous intracranial hypotension: 10 myths and misperceptions. Headache 2018;58:948-59. 